\title{
Blastodinium spp. infect copepods in the ultra-oligotrophic marine waters of the Mediterranean Sea
}

\author{
C. Alves-de-Souza ${ }^{1,2,3}$, C. Cornet ${ }^{1,2,4,5}$, A. Nowaczyk ${ }^{6}$, S. Gasparini ${ }^{4,5}$, A. Skovgaard ${ }^{7}$, and L. Guillou ${ }^{1,2}$ \\ ${ }^{1}$ INSU-CNRS, UMR7144, Station Biologique de Roscoff, Place Georges Teissier, 29682 Roscoff, France \\ ${ }^{2}$ Université Pierre et Marie Curie, UMR7144, Station Biologique de Roscoff, Place Georges Teissier, 29682 Roscoff, France \\ ${ }^{3}$ Instituto de Biología Marina, Universidad Austral de Chile, Campus Isla Teja, P.O. Box 567, Valdivia, Chile \\ ${ }^{4}$ Université Pierre et Marie Curie, UMR7093, Laboratoire d'Océanographie de Villefranche, Villefranche-sur-Mer, France \\ ${ }^{5}$ INSU-CNRS, UMR7093, Laboratoire d'Océanographie de Villefranche, Villefranche-sur-Mer, France \\ ${ }^{6}$ INSU-CNRS, UMR6535, Aix-Marseille Université, Laboratoire d'Océanographie Physique et Biogéochimique, \\ Centre d'Océanologie de Marseille, Campus de Luminy, Case 901, 13288 Marseille, France \\ ${ }^{7}$ University of Copenhagen, Department of Veterinary Disease Biology, Laboratory of Aquatic Pathobiology, Stigbøjlen 7, \\ 1870 Frederiksberg C, Denmark
}

Received: 26 February 2011 - Published in Biogeosciences Discuss.: 11 March 2011

Revised: 25 July 2011 - Accepted: 26 July 2011 - Published: 9 August 2011

\begin{abstract}
Blastodinium are chloroplast-containing dinoflagellates which infect a wide range of copepods. They develop inside the gut of their host, where they produce successive generations of sporocytes that are eventually expelled through the anus of the copepod. Here, we report on copepod infections in the oligotrophic to ultra-oligotrophic waters of the Mediterranean Sea sampled during the BOUM cruise. Based on a DNA-stain screening of gut contents, $16 \%$ of copepods were possibly infected in samples from the Eastern Mediterranean infected, with up to $51 \%$ of Corycaeidae, $33 \%$ of Calanoida, but less than $2 \%$ of Oithonidae and Oncaeidae. Parasites were classified into distinct morphotypes, with some tentatively assigned to species B. mangini, $B$. contortum, and B. cf. spinulosum. Based upon the SSU rDNA gene sequence analyses of 15 individuals, the genus Blastodinium was found to be polyphyletic, containing at least three independent clusters. The first cluster grouped all sequences retrieved from parasites of Corycaeidae and Oncaeidae during this study, and included sequences of Blastodinium mangini (the "mangini" cluster). Sequences from cells infecting Calanoida belonged to two different clusters, one including $B$. contortum (the "contortum" cluster), and the other uniting all B. spinulosum-like morphotypes (the "spinulosum" cluster). Cluster-specific oligonucleotidic probes were designed and tested by fluorescence
\end{abstract}

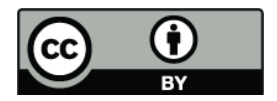

Correspondence to: L. Guillou (laure.guillou@sb-roscoff.fr) in situ hybridization (FISH) in order to assess the distribution of dinospores, the Blastodinium dispersal and infecting stage. Probe-positive cells were all small thecate dinoflagellates, with lengths ranging from 7 to $18 \mu \mathrm{m}$. Maximal abundances of Blastodinium dinospores were detected at the Deep Chlorophyll Maximum (DCM) or slightly below. This was in contrast to distributions of autotrophic pico- and nanoplankton, microplanktonic dinoflagellates, and nauplii which showed maximal concentrations above the DCM. The distinct distribution of dinospores and nauplii argues against infection during the naupliar stage. Dinospores, described as autotrophic in the literature, may escape the severe nutrient limitation of ultra-oligotrophic ecosystems by living inside copepods.

\section{Introduction}

Blastodinium species are gut parasites of a wide range of marine copepods. They have the particularity of being apparently autotrophic dinoflagellates, as they have chloroplasts thought to be functional inside the copepod gut in at least 10 of the 13 species formally described to date (Chatton, 1920; Sewell, 1951; Shields, 1994; Skovgaard and Salomonsen, 2009). Infestation is believed to occur during early stages of the copepod life by the ingestion of small $(<15 \mu \mathrm{m})$ freeliving stages called dinospores (Chatton, 1920, p. 121). This supposition is supported by the failure to produce infection

Published by Copernicus Publications on behalf of the European Geosciences Union. 
inside parasite-free adults exposed to freshly produced dinospores (Skovgaard, 2005). The parasites grow inside the lumen of the alimentary canal, where they develop a quite complex structure. The primary parasitic cell is the trophocyte, a single cell of considerable size (up to several $100 \mu \mathrm{m}$ long), which contains two nuclei and absorbs nutrients. In most cases, this cell undergoes rapid sporogenetic cycles that in some species may occur every day (Chatton, 1920, p. 109). Eventually, the trophocyte divides into a secondary trophocyte and a gonocyte, with both cells remaining inside the outer membrane of the original trophocyte. The gonocyte undergoes sporogony by rapid sequential mitotic divisions producing hundreds of sporocytes. Sporulation starts with the rupture of the membrane, and immature spores, with two nuclei, generally exit the host via the anus. After several series of divisions, mature dinospores with a single nucleus acquire flagella and the typical appearance of peridinioid dinoflagellates (Skovgaard et al., 2007). The fate of these spores is still unknown to date, although they are able to quickly encyst after few days of observation in the laboratory (Chatton, 1920) and rapidly declined when incubated in $f / 2$-enriched seawater (Skovgaard, 2005).

Infections by Blastodinium spp. are not directly lethal but have negative effects on host fitness. For instance, infected populations are reported to be smaller and potentially sterile, with females having immature gonads and undeveloped genital oviducts and males unable to accomplish their final moulting (Sewel, 1951; Chatton, 1920). However, neutering of infected adult females was not always observed (Ianora et al., 1990). Blastodinium reportedly acquires part of its energy from photosynthesis, the rest being ensure by the assimilation of host digestive substances (Pasternak et al., 1984). Thus, the copepod dwarfism and sterility are supposed to be linked to nutritional problems, either provoked by the direct uptake from the parasite or by a reduced capacity to ingest food by the host when Blastodinium trophonts occupy most of the digestive tract (Chatton, 1920, p. 221). On the other hand, the copepod host may in turn benefit from exudates release by the microalgae. However, primary production released from Blastodinium to the host is thought to be low, accounting for only $1 \%$ of the host food demand (Pasternak et al., 1984). In addition, under starvation conditions, survival time of infested copepods is significantly lower than uninfected copepods indicating a negative effect of infection (Skovgaard, 2005).

The majority of Blastodinium species were described by Chatton (1920), mostly from copepods collected in coastal waters of Banyuls-sur-Mer (France, N.W. Mediterranean Sea). Indeed, most observation of Blastodinium species are from warm temperate and tropical waters (Chatton, 1920; Coats et al., 2008; Ianora et al., 1987; Pasternak et al., 1984; Sewell, 1951; Skovgaard and Saiz, 2006). Infection prevalences are generally low (1-10\%), although epizootic outbreaks up to $60 \%$ were reported for the North Sea (Vane, 1952). To date, most studies have focussed mainly on the parasitic stage of Blastodinium spp., growing and sporulating inside the copepod host. However, knowledge concerning the free-living spores released into the water is fundamental to understanding the dynamics of such parasitic infections. Additionally, because dinospores are supposed to be in majority photosynthetically active, production of this biomass escapes to the natural assumption that growth and size of phytoplankton are mainly controlled by nutrient availability.

The main objectives of the BOUM oceanographic cruise (Biogeochemistry from the Oligotrophic to the Ultraoligotrophic Mediterranean), were to simultaneously investigate biochemistry and marine food web structures. This manuscript reports copepod infections by Blastodinium spp. at the three long-term stations of the cruise. We first characterized individual specimens of Blastodinium by morphology and when possible by SSU rDNA gene sequences. These sequences revealed the existence of at least 3 clusters and allowed us to design oligonucleotidic probes specific to the different Blastodinium clusters. Using these probes, we quantified the presence of infective unicellular stages, the dinospores, for each cluster, in the water column between $160 \mathrm{~m}$ depth and the surface. We compared dinospore distribution to a range of biotic and abiotic parameters measured during the BOUM cruise.

\section{Material and methods}

\subsection{Sampling strategy}

The BOUM cruise (Biogeochemistry from the Oligotrophic to the Ultra-oligotrophic Mediterranean sea) took place in the Mediterranean Sea during June-July 2008 and covered a transect from the coastal waters off Marseille (France, West Mediterranean) to the open sea off Israel (East Mediterranean). The three main stations (A, B, and C) located in the Western, Central and Eastern basins, respectively (Fig. 1) were sampled for our study. The stations, while geographically distant, were each inside anticyclonic eddies, characterized by a marked stratification, and very low nutrient levels typical of oligotrophic to ultra-oligotrophic marine waters (Moutin et al., 2010). They were characterized by relatively low concentrations of heterotrophic organisms (bacteria, nanoflagellates, and ciliates) within the microbial food web (Christaki et al., 2011).

Copepods were sampled by a net haul from $200 \mathrm{~m}$ depth to surface at stations A, B and C, using a $120 \mu \mathrm{m}$ mesh Bongo net of $60 \mathrm{~cm}$ of diameter aperture. The samples were subsequently concentrated to less than $50 \mathrm{ml}$ by filtration through a $20 \mu \mathrm{m}$ mesh, rapidly fixed with paraformaldehyde (1\% final concentration) and then stored for one hour at dark and $4{ }^{\circ} \mathrm{C}$. The fixative was removed by filtration using a $20 \mu \mathrm{m}$ mesh and samples were rinsed twice using Phosphate Buffer Saline (PBS). Samples were then stored into PBS/ethanol 1:1 at $-20^{\circ} \mathrm{C}$ into $50 \mathrm{ml}$ flasks. 


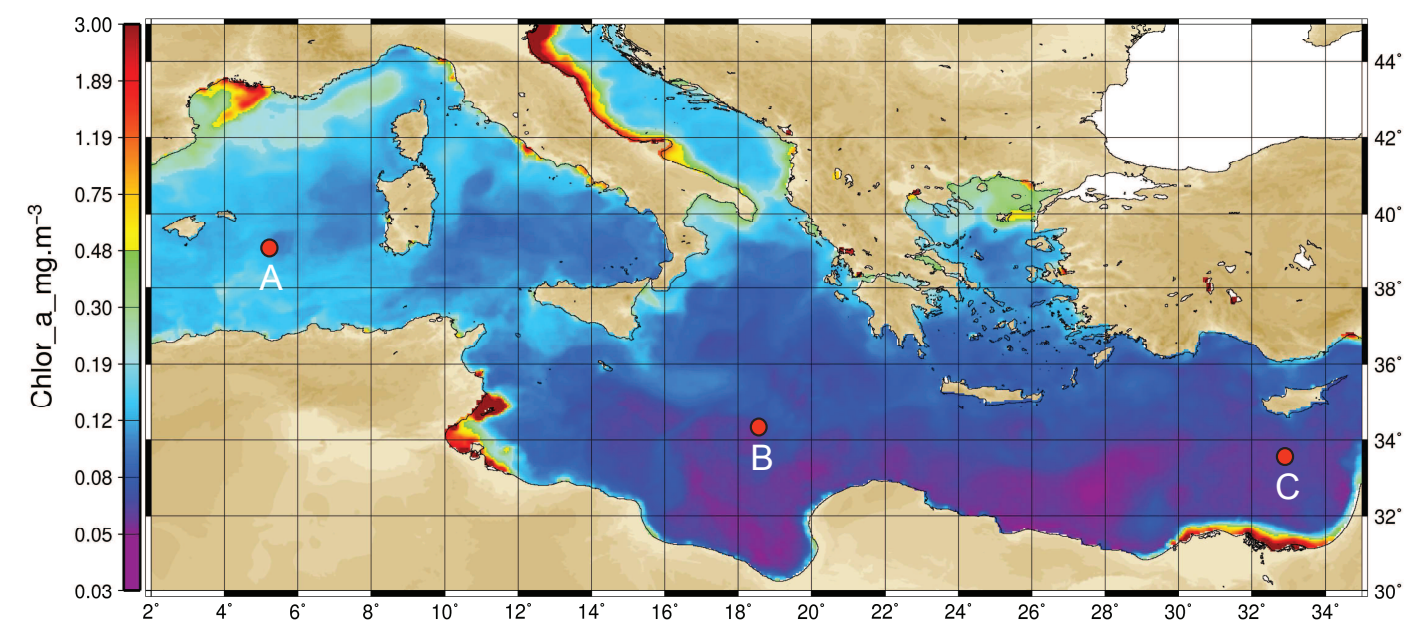

Fig. 1. Location of the stations A, B, and C sampled during the BOUM cruise, superimposed on a SeaWIFS ocean color composite indicating values of total chlorophyll- $a$ (15 June-15 July 2008).

Water column samples were taken at 5-6 discrete depths between from 5 to $160 \mathrm{~m}$ using 121 Niskin bottles on a rosette equipped with a conductivity-temperature-depth (CTD) and fluorescence sensors. These water samples were used for the enumeration of Blastodinium dinospores by fluorescent in situ hybridization method (FISH). Fifty to $200 \mathrm{ml}$ were fixed with paraformaldehyde (1\% final concentration) and stored for one hour in the dark at $4{ }^{\circ} \mathrm{C}$. Fixed seawater was filtered onto $0.22 \mu \mathrm{m}$ Anodisc filters (Whatman) with a vacuum pump $(\sim 200 \mathrm{~mm} \mathrm{Hg})$. The filters were dehydrated in an ethanol series $(50 \%, 80 \%, 100 \% ; 3$ min each), briefly dried at room temperature, and stored at $-80^{\circ} \mathrm{C}$.

\subsection{Detection of infections and SSU rDNA gene sequencing}

Blastodinium spp. can be easily detected inside the copepod gut in fresh specimens based on the brownish-greenish color and chlorophyll autofluorescence of the photosynthetic parasite (Skovgaard, 2005). However, our fixation protocol uses ethanol to maximise sequencing success and destroys chlorophyll. Consequently, we developed a method based on DNA staining with propidium iodide (PI, $10 \mu \mathrm{g} \mathrm{ml}^{-1}$ ) to detect infections. As dinoflagellates have typical, characteristic condensed chromatin at all stages of their life cycle, DNA staining allowed us to easily distinguish Blastodinium nuclei from those of the host tissues. This method detected mature and sporulating individuals but was probably less suitable to detect early stages of infections (young trophocytes).

The most abundant copepod taxa were divided into four groups, i.e. Calanoida, Corycaeidae, Oncaeidae and Oithonidae. For each group, copepods were randomly selected and single individuals placed into a 96 well culture plate (Nalgene) containing PBS/ethanol 1:1. After DNA staining, copepods were examined using an inverted micro- scope equipped with an epifluorescence light source (Olympus, IX71) and a fluorescent filter set for IP (excitation: $536 \mathrm{~nm}$; emission: $617 \mathrm{~nm}$ ) to determine the presence or absence of Blastodinium. In order to evaluate if Blastodinium infection affected copepod development, the prosome sizes of infected and uninfected individuals (Corycaeidae only) were compared through Mann-Whitney analyses. This test was used because data were not normally distributed and not homocedastic. From Station C, some of the infected individuals were individually transferred into $0.5 \mathrm{ml}$ tubes and stored in PBS/ethanol 1:1 at $-20^{\circ} \mathrm{C}$ for further examination. Dissections were done under a steroscope. The very top of the copepod head was finely cut using a scalpel, and Blastodinium individuals were extracted from the copepod gut by gently lacerating the gut. When possible, Blastodinium were photographed using a standard microscope equipped with a camera (Olympus, BX51). Large sporulating Blastodinium generally fragmented during copepod dissection and sporocytes were directly placed into microtubes for subsequent genetic analyses. Parasites were either solitary or gregarious (i.e. more than one individual per copepod). All Blastodinium individuals extracted from the same copepod host were pooled inside the same tube. Blastodinium individuals were also found outside of their copepod host, probably due to damaging the host through manipulation. These specimens were also placed into $0.5 \mathrm{ml}$ tubes for DNA extraction. Infected copepods were also stained using Gill's Hematoxylin (Polysciences, Inc., Warrington, PA 18976, USA) and then photographed.

DNA was extracted from individual parasites using a modified GITC (Guanidinium isothiocyanate, protocol (Chomczynski and Sacchi, 2006). Individuals were placed in $50 \mu \mathrm{l}$ of the GITC extraction buffer and crushed using an adjusted micro-pilon (Kimble Chase ${ }^{\circledR}$ ). Tubes were incubated at $72{ }^{\circ} \mathrm{C}$ for $20 \mathrm{~min}$. Next, one volume of cold isopropanol was 
Table 1. List of primers and probes used in this study.

\begin{tabular}{lll}
\hline Name & Sequence & Purpose \\
\hline 18S 328F & 5' ACCTGGTTGATCCTGCCAG 3' & Primer for PCR in forward \\
18S 528F & 5' CCGCGGTAATTCCAGCTC 3' & Primer for PCR in forward and sequencing \\
18S 63F & 5' ACGCTTGTCTCAAAGATTA 3' & Primer for PCR in forward \\
18S 329R & 5' GTGAACCTGCRGAAGGATCA 3' & Primer for PCR in reverse \\
18S 1818R & 5' ACGGAAACCTTGTTACGA 3' & Primer for PCR in reverse \\
18S 18r71 & 5' GCGACGGGCGGTGTGTAC 3' & Primer for PCR in reverse \\
18S 690R & 5' ATCCAAGAATTTCACCTCTGAC 3' & Primer for sequencing \\
18S 1055F & 5' GGTGGTGCATGGCCGTTCTT 3' & Primer for sequencing \\
18S 1055R & 5' ACGGCCATGCACCACCACCCAT 3' & Primer for sequencing \\
BMANG1 & 5' CACTCTCCAAGAAGATGC 3' & Specific probe for Blastodinium, clade “mangini”" \\
BCON2 & 5' CATACAGTCAAGCACAGC 3' & Specific probe for Blastodinium, clade “contortum” \\
BLA2 & 5' TGCGCTAGACGCACAAGG 3' & Specific probe for Blastodinium, clade “spinulosum” \\
\hline
\end{tabular}

added at $-20^{\circ} \mathrm{C}$ overnight for DNA precipitation. The following day, samples were centrifuged $(14000 \mathrm{rpm}, 15 \mathrm{~min}$ at $4{ }^{\circ} \mathrm{C}$ ) and supernatants removed. The DNA pellet was cleaned using $70 \%$ ethanol $(100 \mu \mathrm{l})$, followed by a last centrifugation $(14000 \mathrm{rpm}, 10 \mathrm{~min})$. Supernatant was removed and the DNA pellet was hydrated into $20 \mu \mathrm{l}$ of sterile distilled water and stored at $-20^{\circ} \mathrm{C}$.

DNA extraction products were used for PCR amplification of SSU rDNA (or 18S) gene using different combinations of primers (Table 1$)$. The PCR mix (15 $\mu$ f final volume) contained $1-6 \mu \mathrm{l}$ of the DNA extract, $330 \mu \mathrm{M}$ of each deoxynucleoside triphosphate (dNTP), $2.5 \mathrm{mM}$ of $\mathrm{MgCl}_{2}, 1.25 \mathrm{U}$ of GoTaq ${ }^{\circledR}$ DNA polymerase (Promega Corporation), $0.17 \mu \mathrm{M}$ of both primers, $1 \times$ of buffer (Promega Corporation). The PCR cycle, run in an automated thermocycler (GeneAmp® PCR System 9700, Applied Biosystem), was programmed to give an initial denaturating step at $95^{\circ} \mathrm{C}$ for $5 \mathrm{~min}, 35 \mathrm{cy}$ cles of denaturating at $95^{\circ} \mathrm{C}$ for $1 \mathrm{~min}$, annealing at $55^{\circ} \mathrm{C}$ for $45 \mathrm{~s}$ and extension at $72^{\circ} \mathrm{C}$ for $1 \mathrm{~min} 15 \mathrm{~s}$, and a final extension step at $72^{\circ} \mathrm{C}$ for $7 \mathrm{~min}$. PCR products were cloned into a TOPO TA cloning kit (Invitrogen ${ }^{\circledR}$ ), following manufacturer's recommendations. Inserts inside white colonies were screened by PCR (same procedure as before). Positive PCR products were purified (ExoSAP-IT ${ }^{\circledR}$ For PCR Product Clean-Up, USB ${ }^{\circledR}$ ) and sequenced using the Big Dye Terminator Cycle Sequencing Kit version 3.0 (PE Biosystems ${ }^{\circledR}$ ) and an ABI PRISM model 377 (version 3.3) automated sequencer with specific primers. Sequences were edited in the BioEdit 7.0.5.3 program and complete sequences deduced from runs using both external and internal primers (Table 1).

\subsection{Phylogeny}

Available sequences were aligned using the online version 6 MAFFT, (http://mafft.cbrc.jp/alignment/software/ index.html). The best nucleotide substitution model was determined using JModeltest 0.1.1 (Posada, 2008) and a transitional model with six free parameters and unequal base frequencies (TIM $2+\mathrm{G})$ was selected with the following parameters: Lset base $=\left(\begin{array}{llll}0.2622 & 0.1894 & 0.2606\end{array}\right.$ 0.2878$), \quad$ rmat $=\left(\begin{array}{lllll}1.4098 & 3.4396 & 1.4098 & 1.0000 & 8.3362\end{array}\right.$ 1.0000 ), shape $=0.4100$. Maximum Likelihood was conducted using PhyML 3.0 (Guindon et al., 2005) and the robustness of inferred topology was supported by bootstrap resampling (100). Bayesian inference was conducted using MrBayes 3.1.2 (Huelsenbeck and Ronquist, 2001) and started with a random tree, run for 2000000 generations, sampling the chains every 100th cycle, and burn-in of 5000 generations in order to ensure the use of only stable chains. Data remaining after discarding burn-in samples were used to generate a majority-rule consensus tree where the percentage of samples recovering any particular clade of the consensus tree represented the clade's posterior probability (Huelsenbeck and Ronquist, 2001). The sequences obtained during this study have been deposited in GenBank (JN257667JN257681).

\subsection{Detection of dinospores by FISH}

Oligonucleotide probes were designed after visual inspections of the previously described aligned sequences. Beside specificity, main criteria for probe construction were a length of 18 mers and GC content $\geq 50 \%$. Probe specificity was tested in silico on a database containing more than 150000 sequences of SSU rDNA, including 3400 dinoflagellate sequences. Positive controls were obtained using sporulating Blastodinium extracted from copepods by disrupting the external cuticle. Dinospores were placed inside PBS:ethanol 50:50 and then filtered throughout a $5 \mu \mathrm{m}$ polycarbonate filter and dehydrated as previously described.

Oligonucleotide probes were purchased directly labelled with horseradish peroxidase (HRP) in complement to tyramide signal amplification (FISH-TSA). FISH-TSA was 
performed separately for each probe. Anodisc filters with samples or positive controls were thawed and cut into pieces (ca. 1/4). For each piece of filter, the face supporting the cells was marked with a pen. Filters were covered with $18 \mu \mathrm{l}$ of $40 \%$ formamide hybridization buffer $(40 \%$ deionized formamide, $0.9 \mathrm{M} \mathrm{NaCl}, 20 \mathrm{mM}$ Tris- $\mathrm{HCl} \mathrm{pH} 7.5$, $0.01 \%$ sodium dodecylsufate (SDS), $10 \%$ Blocking agent (Boehringer Mannheim) and $2 \mu \mathrm{l}$ of oligonucleotide probe (50 ng $\mu \mathrm{l}^{-1}$ final concentration). Filters were incubated for $3 \mathrm{~h}$ at $35^{\circ} \mathrm{C}$ for hybridization and subsequently washed twice at $37^{\circ} \mathrm{C}$ during $20 \mathrm{~min}$ with $3 \mathrm{ml}$ freshly made washing buffer ( $56 \mathrm{mM} \mathrm{NaCl}, 5 \mathrm{mM}$ EDTA, $0.01 \%$ SDS, $20 \mathrm{mM}$ Tris$\mathrm{HCl} \mathrm{pH} \mathrm{7.5).} \mathrm{Filters} \mathrm{were} \mathrm{then} \mathrm{equilibrated} \mathrm{in} 3 \mathrm{ml}$ TNT buffer $(100 \mathrm{mM}$ Tris- $\mathrm{HCl} \mathrm{pH} 7.5,150 \mathrm{mMNaCl}, 0.05 \%$ Tween 20) for $15 \mathrm{~min}$ at room temperature in the dark. Each piece of filter was transferred onto a slide for TSA reaction (Kit NEN Life Science Products); $20 \mu \mathrm{l}$ of freshly made TSA mix (1:1 dextran sulfate and amplification diluent, 1:50 fluorescein tyramide and the mixture of dextran sulfate) were put on the top of each filter piece and slides were incubated for $30 \mathrm{~min}$ in the dark. In order to stop the enzymatic reaction and wash the filters, they were transferred in two successive $5 \mathrm{ml} 55^{\circ} \mathrm{C}$ pre-warmed TNT buffer baths for $20 \mathrm{~min}$ each. Filters were then rinsed in water, dried at $55^{\circ} \mathrm{C}$ and counterstained with calcofluor $\left(100 \mathrm{ng} \mathrm{ml}^{-1}\right)$ for visualization of dinoflagellate theca. Slides were covered with a cover glass, together with a mix of the antifading reagent Citifluor AF1 and PI for visualization of nucleus $\left(10 \mu \mathrm{g} \mathrm{ml}^{-1}\right)$, sealed with nail varnish and stored at $4{ }^{\circ} \mathrm{C}$ in the dark. All hybridized and stained filters were observed with an Olympus BX-51 epifluorescence microscope (Olympus Optical) equipped with a mercury light source, a 11012v2-Wide Blue filters set (Chroma Technology, VT, USA) and a CCD camera (Spot-RT, Diagnostic Instrument, Sterling Heights, MI, USA). Cells were observed with fluorescence filters sets for calcoluor (excitation: $345 \mathrm{~nm}$; emission: $455 \mathrm{~nm}$ ), PI (excitation: $536 \mathrm{~nm}$; emission: $617 \mathrm{~nm}$ ) and fluorescein tyramide (excitation: $495 \mathrm{~nm}$; emission: $520 \mathrm{~nm}$ ). For each probe, Blastonidium dinospores, and small thecate dinoflagelates (STD) were counted on the entire surface representing about $1 / 4$ of the original filter at $40 \times$ magnification. After the counting, the pieces of filter were photographed and the precise area was calculated using ImageJ software in order to estimate cell abundances.

\subsection{Statistical analysis}

The possible relationship between Blastodinium dinospore abundances and other abiotic and biotic variables, i.e. nauplii abundances (Nowaczyk et al., 2011), microplanktonic dinoflagellates (Z. Gomez et al., personal communication, 2010), tintinnids (J. Dolan, personal communication, 2010), autotrophic pico- and nanoeukaryotes (C. Courties and L. Bariat, personal communication, 2010), and total eukaryotes (Siano et al., 2011) were examined using Spearman cor- relation analysis. All the statistical analyses were performed using Statistica 6.0 (StatSoft). Prior to the analyses, all abundance data were $\log$-transformed $[\ln (x+1)]$.

\section{Results}

\subsection{Copepod infections by Blastodinium spp.}

At Station $\mathrm{C}$, low infection frequencies $(<2 \%)$ were estimated for Oithonidae $(n=60)$ and Oncaeidae $(n=96)$. In contrast, up to $51 \%$ of Corycaeidae $(n=96)$ and $33 \%$ of Calanoida (Clausocalanus and Paracalanus, $n=84$ ) appeared infected based on results of the DNA-stain screening test. These groups represented $86.8 \%$ of the total copepod communities (Nowaczyk et al., 2011). Overall, $16 \%$ of copepods were possibly infected at this station.

Infections of Corycaeidae indicated by the DNA-screening method were further confirmed by dissections in 30 of 35 randomly selected individuals. Among Calanoida, the genus Clausocalanus was one of the most abundant groups with at least four species; C. furcatus, C. paululus, C. parapergens, and $C$. jobei. Among them, $C$. furcatus and $C$. parapergens were observed to be infected (list not exhaustive). The Corycaeidae was dominated by a single species, Farranula rostrata, although Corycaeus sp. and Onchocorycaeus sp. were also observed. Males and females of Corycaeidae, distinguishable by the shape of their genital segment, were equally infected. The mean prosome length of females suspected to be infected was $536.1 \mu \mathrm{m} \pm 29.5 \mu \mathrm{m}$ $(n=33)$ compared to $551 \pm 61.7 \mu \mathrm{m}(n=26)$ when uninfected. In males, the mean prosome length of individuals suspected to be infected was $459 \mu \mathrm{m} \pm 52.2 \mu \mathrm{m}(n=22)$ and $517.9 \mu \mathrm{m} \pm 47.6 \mu \mathrm{m}(n=24)$ when uninfected. However, Mann-Whitney analyses indicated that for both sexes the differences between infected and uninfected individuals were not significant $(P=0.086)$. Infections of Corycaeidae were lower at stations $\mathrm{A}$ and $\mathrm{B}$, with only 8 and $18 \%(n=96)$ positively screened by the DNA-staining method, respectively (data not available for other groups).

A total of 51 Blastodinium individuals were isolated from station $\mathrm{C}$ which were either obtained from copepod dissections or found directly in the samples outside their hosts. They differed in location inside the gut of the host as well as their general shape (Fig. 2). Blastodinium infecting Corycaeidea were elongated (Fig. 2a) or globular (Fig. 2b and c) and were located anterior-dorsal (Fig. 2b), to dorsoventral (Fig. 2c). Within Calanoidea, parasites were globular (Fig. 2d), spirally-twisted (Fig. 2e and g), or spindle-shaped (Fig. 2f). When observed inside their host, spirally-twisted individuals were always solitary (see Fig. 2h). Figure 3 represents spindle-shaped Blastodinium morphotypes, rounded at the anterior pole and more or less pointed at the posterior pole. Exceptions were individuals that had cylindrical to horizontal extremities on both sides (Fig. $3 \mathrm{~h}$ and i). In 


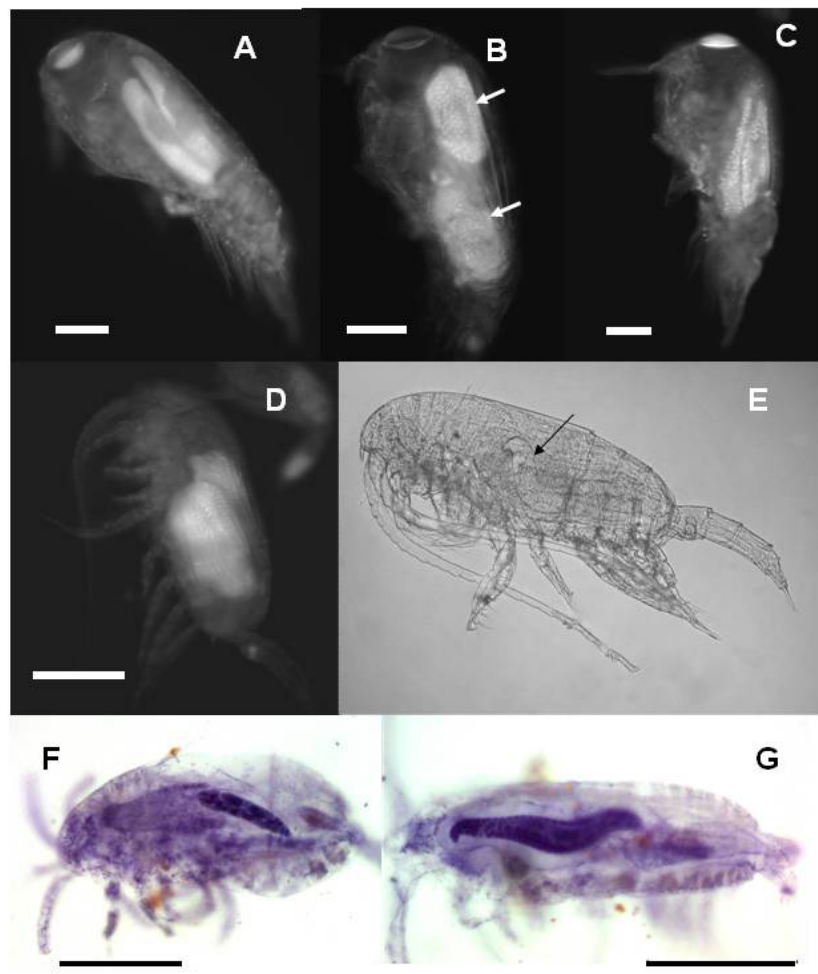

Fig. 2. Observations of Blastodinium spp. located inside the gut of their hosts. (A) Three individuals of Blastodinium mangini infecting Farranula cf. rostrata (BOUM19). (B) At least two individuals (arrows) of an unknown Blastodinium with a globular shape infecting Farranula cf. rostrata (BOUMD9). (C) Unknown Blastodinium infecting Farranula cf. rostrata (BOUM18). (D) Two individuals of an unknown Blastodinium with a globular shape infecting Clausocalanus furcatus (BOUM17). (E) Blastodinium contortum infecting Clausocalanus furcatus (BOUMB). (F) Blastodinium cf. spinulosum infecting a probable Clausocalanus sp. (G) Hypertwisted Blastodinium contortum infecting a probable Haloptilus sp. Individuals from (A) to (D) were observed after DNA-staining by Propidium Iodide. Individuals from $(\mathbf{F})$ and $(\mathbf{G})$ were stained using Gill's Hematoxylin. Scale bars $=100 \mu \mathrm{m}$.

most cases, a more or less marked straight or concave face (called the ventral side) and a rounded or convex face (the dorsal side) were easily observable (as examples Fig. 3a, b and d). All Blastodinium individuals observed were sporulating, and thus were surrounded by one or several layers of sporocytes. In some cases, the trophocyte apical to median was still visible and in direct contact with the external cuticle (Fig. 3a and b for examples), a region that was called the hilum by Chatton (1920, the hile in French). When visible, these trophocytes were dorsal (Fig. 3a, b, c, e and g) except in one individual which showed a ventral trophocyte (Fig. 3d). More or less pronounced twisted morphotypes are showed in the Fig. 4a-c, formed by one and half (Fig. 4b-c) to two (Fig. 4a) turns of a spiral. The trophocyte was more or less central, surrounded by several generations of sporocytes. A

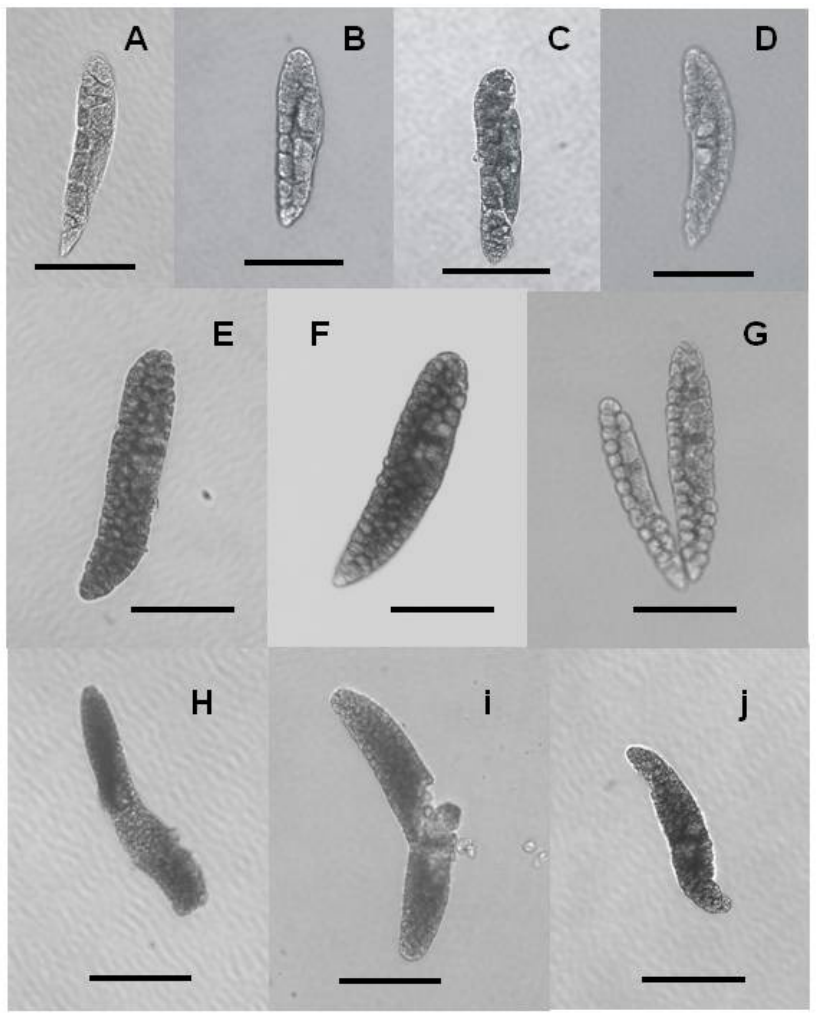

Fig. 3. Different morphotypes of Blastodinium spp. with a spindle shape. (A): BOUM5, (B): BOUM27, (C): BOUM21, (D): BOUM29, (E): BOUM3, (F): BOUM35, (G): BOUMPARE4 (see also Fig. S1), (H): BOUM19 (see also Fig. 2), (I): BOUM26, (J): BOUM4. Scale bars $=100 \mu \mathrm{m}$.

presence of the hilum was clearly noticed for Fig. 4b. The largest individual was BOUM7 ( $470 \mu \mathrm{m}$ in length, Fig. $4 d$ ). This diblastic individual was characterised by the extreme position of its trophocyte that emerged at the anterior pole.

\subsection{Phylogeny}

A total of 15 Blastodinium individuals were successfully amplified by PCR and sequenced. Among them, five were extracted from Corycaeidae, two from Calanoida, one from Oncaea sp., and six from individuals found outside their hosts. Four of them (BOUM21, BOUM27, BOUMPARE4, and BOUMF5) could not be amplified using the most external primers (primer $528 \mathrm{~F}$ was used in forward, Table 1) and consequently these sequences were shorter than others (1157 to $1173 \mathrm{bp}$ ) and not included in Fig. 5.

The fifteen sequences belong to the Dinoflagellata. Both Bayesian and Maximum Likelihood (ML) inferences separated Blastodinium sequences into three main clusters (Fig. 5). All sequences obtained from Corycaeida and Oncaeidae, grouped into a first cluster well supported by Bayesian posterior probabilities and ML bootstrap values. This cluster also grouped with published sequences of $B$. 


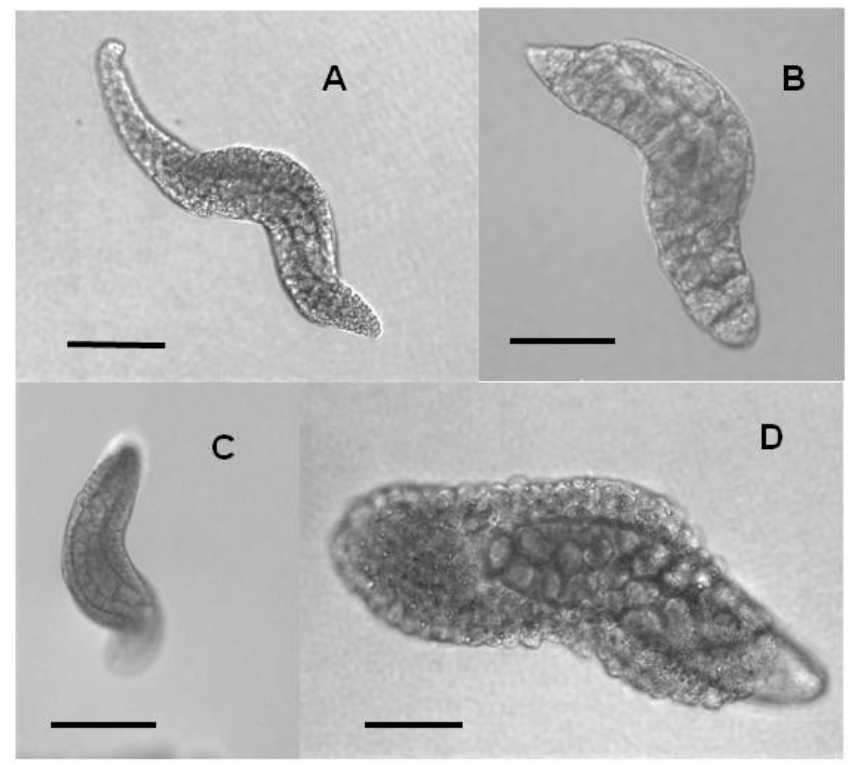

Fig. 4. Different morphotypes of Blastodinium spp. showing a more or less pronounced spirally twisted shape. (A): BOUM8, (B): BOUM37, (C): BOUM50, (D): BOUM7. Scale bars $=50 \mu \mathrm{m}$.

navicula and of B. galatheanum (Skovgaard et al., 2007; Skovgaard and Salomonsen, 2009). Within this group, sequences BOUM4, 19 and 26 had more than $99 \%$ nucleotide sequence identities. All other sequences (BOUME4, BOUMD9, BOUMF5, and BOUMB12) were not particularly affiliated to other sequences within this cluster. A second cluster was formed by all available sequences of $B$. spinulosum, B. inornatum, and B. crassum from one part, and sequences BOUMPARE4, 3, 21, 27, 29 and 35 in other part. This cluster was only supported by Bayesian posterior probabilities. BOUMPARE4 (not in Fig. 5) was closely related to BOUM35, with a $99.8 \%$ sequence identity. Finally, a last cluster grouped all sequences of $B$. contortum available to date and individual BOUM50 from this work, with high statistical supports. Sequence BOUM7 was completely separated from the rest of Blastodinium sequences, and grouped with other dinoflagellate sequences with a long branch.

\subsection{Detection of dinospores}

A general probe specific for the entire Blastodinium genus and targeting all available sequences could not be designed, in agreement with the apparent polyphyletic nature of the genus. Consequently, three different probes were designed for the main clusters described above (probes BMANG1, BLA2, and BCON2, Fig. 5). Probes BMANG1 and BCON2 perfectly matched all known sequences of their groups. Considering only sequences long enough to cover the portion of the probe, 8 out of the 12 sequences belonging to the second cluster perfectly matched the probe BLA2. Indeed, this probe had 1 to 2 mismatches with sequences BOUM3, 21, 27 and the environmental sequence AY664982. However, this probe was the best motif detected for this cluster.

In addition to an intensive in silico screening (see the methods), the specificity of these probes was tested by fluorescent in situ hybridization (FISH) on Blastodinium individuals directly extracted from copepods. Based upon previous results, several parasites extracted from Corycaeida were pooled onto the same filter (considered to be the targeted cells for probe BMANG1). Blastodinium extracted from Calanoida were separated into two categories, more or less straight individuals in one part (considered as positive cells for BLA2) and more or less spirally twisted in other (considered as positive cells for BCON2). Sporocytes of these parasites were isolated from the external cuticle and prepared for FISH analyses (see material and methods section). The three specific probes were individually tested. Positive signals were only detected between cluster-specific probes and their corresponding Blastodinium morphotypes. These three probes were then tested on microphytoplankton collected at stations $\mathrm{A}, \mathrm{B}$, and $\mathrm{C}$, containing various species belonging to Dinophysiales, Gonyaulacales, Prorocentrales, and Peridiniales (similar filters as were processed by Siano et al., 2010). No positive signal was detected.

From water column samples, all probe-positive cells were small thecate dinoflagellates (STD) with a single more or less diffuse condensed nucleus, evidenced by the calcofluor and the IP stains (Fig. 5b-d). Most of these cells had a relatively large transversal cingulum. Thecae were relatively thick for cells targeted by probes BCON2 and BMANG1. This was not the case for majority of BLA2-targeted cells, which exhibited thinner thecae (Fig. 5c). The smallest cells were detected using the probe BMANG1 $(7-10 \mu \mathrm{m}$ in length and 5$10 \mu \mathrm{m}$ in width), whereas larger cells were observed using the probe BCON2 (11-18 $\mu \mathrm{m}$ in length and $9.5-13 \mu \mathrm{m}$ in width). Beside these general characteristics, a given probe was associated with several distinct morphotypes, especially within the BMANG1 cluster (Fig. 5b).

BLA2 targeted cells were the most abundant, peaking at 2.2 cells ml ${ }^{-1}$ at $100 \mathrm{~m}$ depth in station A. BMANG1 probepositive cells were lower in abundance, with a maximal density of 0.83 cells ml ${ }^{-1}$ observed at station A at $110 \mathrm{~m}$. Finally, maximal abundance of BCON2 targeted cells was observed at station B and for $160 \mathrm{~m}$, with 0.84 cells ml$^{-1}$. BMANG1 targeted cells were not observed in surface, whereas cells targeted by probes BCON2 and BLA2 were detected at $12.5 \mathrm{~m}$ at stations B and C. The sum total of cells targeted by the 3 probes followed the vertical distribution of total STD, which ranged from 3.3 cells ml ${ }^{-1}$ at station $\mathrm{C}$ to 7.3 cells ml $^{-1}$ at station B. Maximum densities of STD were detected 10 to $20 \mathrm{~m}$ below the deep chlorophyll maximum at stations A and C and at the DCM at station B (Fig. 6). FISH-positive cells represented a substantial proportion of STD communities at their maximal abundances $(56 \%$ at station $\mathrm{A}$ and $26 \%$ at stations B and C). 


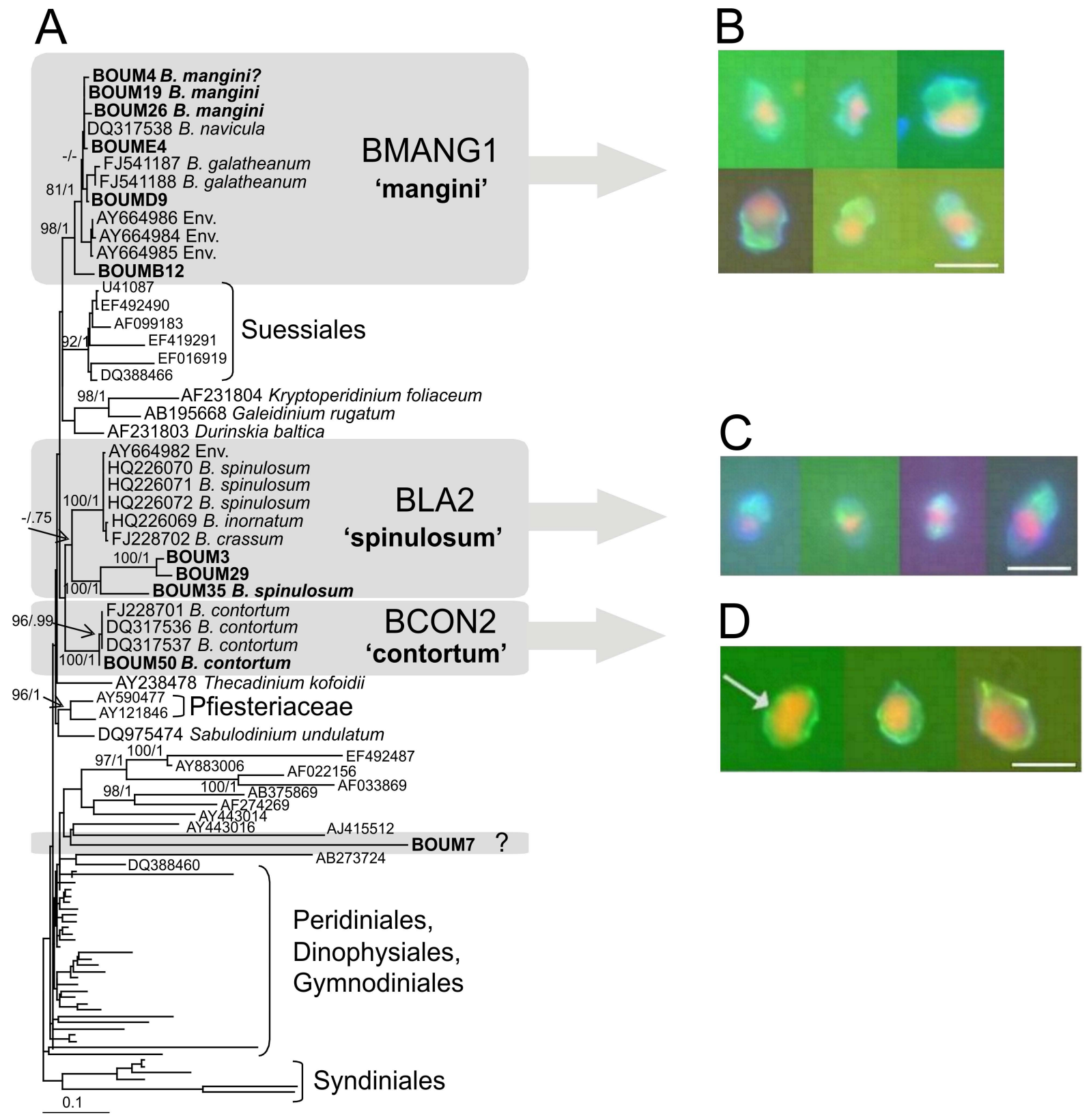

Fig. 5. Phylogeny of Blastodinium spp. and detection of dinospores by fluorescent in situ hybridization. (A) Maximum likelihood analyses of SSU rDNA gene sequences of Blastodinium spp. Sequences obtained in this study are in bold. Complete list of sequences available in Supplement (Table S1). Maximum likelihood bootstrap values (higher than $70 \%$ ) and posterior probabilities of Bayesian inferences (higher than 0.7) are reported at the nodes of the principal clusters, respectively. Scale bar corresponds to 0.1\% divergence. (B) Blastodinium dinospores observed in BOUM samples using the probe BMANG1, specific for the "mangini" cluster. (C) Blastodinium dinospores observed in BOUM samples using the probe BLA2, specific for the "spinulosum" cluster. (D) Blastodinium dinospores observed in BOUM samples using the probe BCON2, specific for the "contortum" cluster. Scale bars $=10 \mu \mathrm{m}$.

Blastodinium dinospores were negatively correlated with copepod nauplii $(-0.54 ; P<0.001)$, which were observed mainly above the DCM at station $\mathrm{A}, \mathrm{B}$, and $\mathrm{C}$, with similar concentrations during night and day. Similarly, negative correlations were detected between dinospores and other phytoplankton communities mainly occurring above the DCM, such as autotrophic pico- $(-0.55)$ and nanoplankton $(-0.58)$ and total eukaryotes $(-0.60 ; P<0.001)$. No correlation was detected between Blastodinium dinospores, microplanktonic dinoflagellates, and tintinnids. 

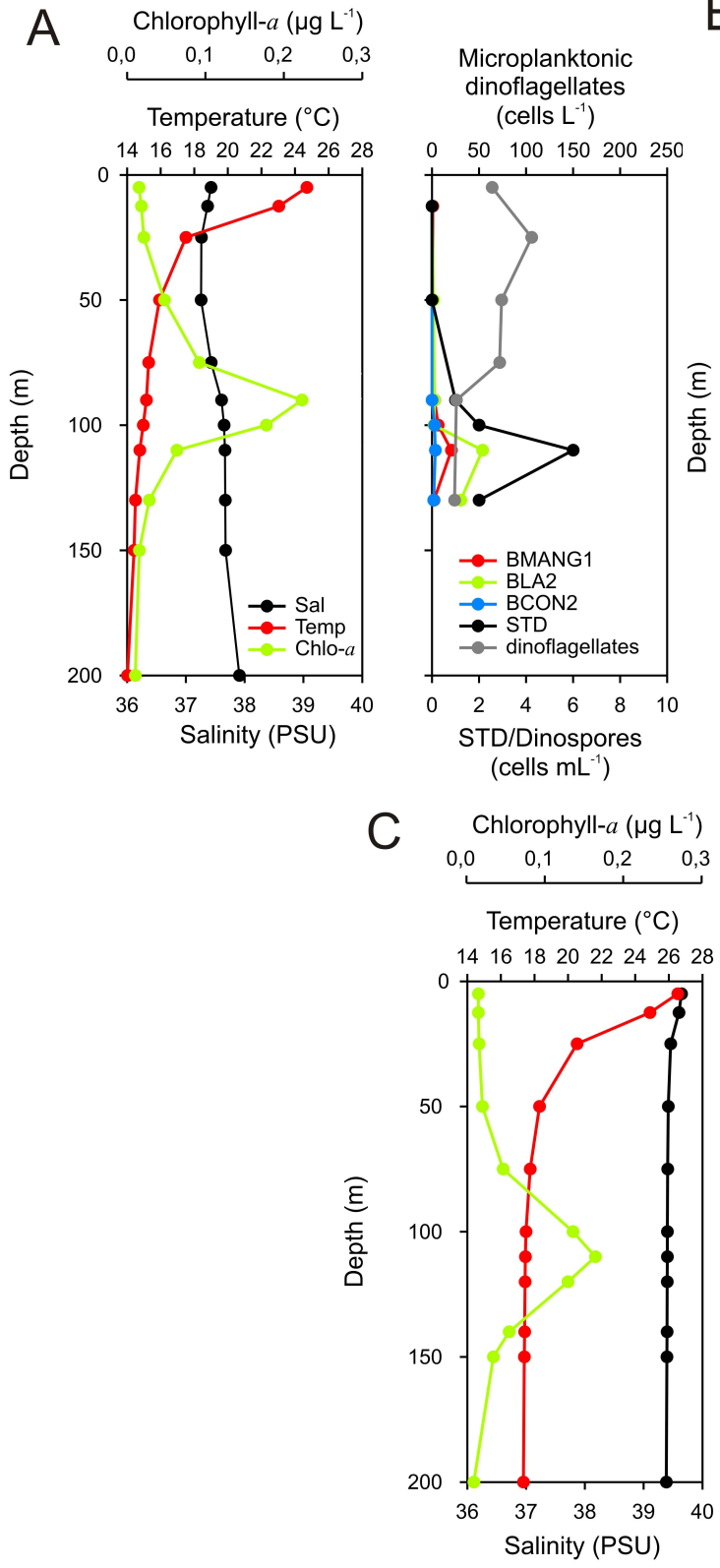

B

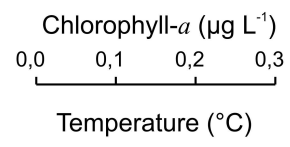
Microplanktonic
dinoflagellates

(cells $\mathrm{L}^{-1}$ )

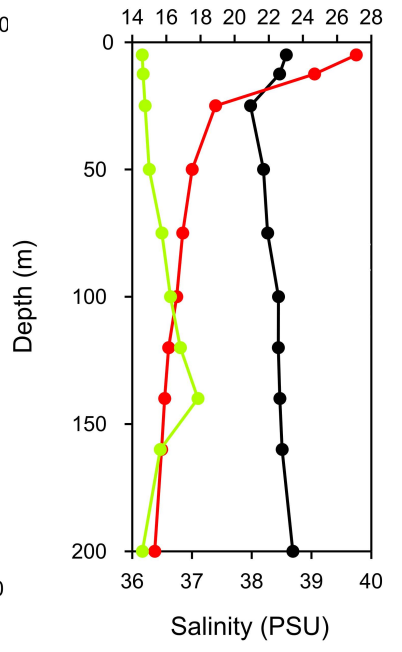

$\begin{array}{r}0 \quad 100150200250 \\ \hline\end{array}$

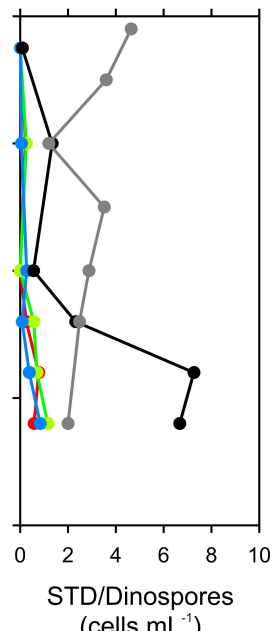

(cells $\mathrm{mL}^{-1}$ )

\section{Microplanktonic dinoflagellates (cells L-1)}

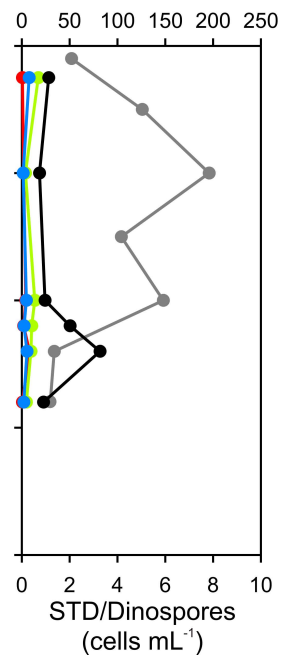

Fig. 6. Vertical distribution of abiotic and biotic parameters at sampling stations A, B, and C. Panels at left: total chlorophyll- $a$ ( $\mu \mathrm{g} 1^{-1}$ ), Temperature $\left({ }^{\circ} \mathrm{C}\right)$, and Salinity (PSU). Panels at right: total abundances of microplanktonic dinoflagellates (cells $\left.1^{-1}\right)$, Small thecate dinoflagellates (STD, cells $\mathrm{ml}^{-1}$ ), and Blastodinium dinospores detected by fluorescent in situ hybridization using corresponding probes (BMANG1, BLA2, and BCON2, cells $\mathrm{ml}^{-1}$ ).

\section{Discussion}

\subsection{Identification of parasites}

Species within the genus Blastodinium are distinguished based on the cell shape and size, the location of the trophocyte in sporulating individuals, and the presence or absence of a helicoidal crest of small spinules at the surface of the trophocyte, although this last criterion is often difficult to observe using classical microscopy (Coats et al., 2008; Sewell,
1951). We found that some parasites were characteristic enough to be tentatively assigned to known species. This was the case for individuals BOUM19 and BOUM26, typical of $B$. mangini with a spindle-shape with almost rounding posterior ends, cylindrical to truncate, and lengths ranging from 200 to $350 \mu \mathrm{m}$ (Chatton, 1920, p. 163). Chatton (1920) described this species as found exclusively in Farranula rostrata in Banyuls-sur-Mer (Chatton, 1920, p. 161), as was also the case at Station C. Blastodinium mangini is gregarious, 
mostly observed in groups of three individuals, as it was also the case for individual BOUM19. In Banyuls-sur-Mer, this species was frequently observed in September-October, infesting up to $10 \%$ of the host populations (Chatton, 1920). A closely related morphotype infecting Oncaea media was also described as the variety $B$. mangini var. oncae (Chatton, 1920). However, Sewell (1951) remarked that B. mangini and $B$. mangini var. oncae could not be distinguished based upon morphological criteria. Indeed, Sewell (1951) illustrated a large degree of morphological variability and some of them could be well in the range of the observed globular individuals (Fig. 2b and S1). SSU rDNA failed to properly separate taxa within this cluster, as suggested by the interconnection of other species such as B. navicula and $B$. galatheanum in Fig. 5, and more sequences from more variable genetic regions are required to settle this point.

All S-shaped spirally twisted individuals (Fig. 4a to c) were in the range of morphological variation described for B. contortum. This identification was also confirmed by the close relationship between sequence BOUM50 and all sequences of $B$. contortum available in the public databases. Indeed, individuals BOUM50 and BOUM37 were typical, solitary inside their host, the cell twisted into a helix in one and a half turns. The sizes were also in the range of this species (150-350 $\mu \mathrm{m}$ for diblastic stages, Chatton, 1920). Individual BOUM8 (Fig. 2g) was closest to the larger morphotype "hypertwisted" (300-400 $\mu \mathrm{m}$ with at least two turns of the helix) described by Chatton. Paracalanus parvus is the host type for $B$. contortum. However, this species is known from a wide range of calanoid hosts, including $C$. furcatus and C. arcuicornis (Chatton, 1920; Sewell, 1951).

The parasite BOUMPARE4 was also tentatively assigned to $B$. cf. spinulosum for several reasons. First, this species is gregarious (11 individuals were retrieved from the same copepod host) and its general shape and size was typical for this species: a spindle shape, two well differentiated poles, with a marked pointed posterior end, and the trophocyte generally submedian and posterior, size of 150-280 $\mu \mathrm{m}$ (Chatton, 1920). Clausocalanus furcatus, the most common host for this species, was well represented in BOUM samples. However, the relative distance between all sequences retrieved from the BOUM cruise and sequences of $B$. crassum, $B$. inornatum, and $B$. spinulosum prevented placing this parasite within $B$. spinulosum. Again, more variable regions are required to unveil affiliations within the group.

Other parasites had very unusual features. In particular, individuals BOUM21 and 27 have relatively rounded posterior pole and BOUM29 have a very unusual position for the trophont forming a hilum in ventral position (Fig. 3). BOUM7 is similar in shape and size to Blastodinium sp. $\gamma$ described by Chatton (1920, p. 205). However, because the host was unknown and because of the long branch of this sequence in phylogenetic analyses, identification of this individual was not possible nor its eventual classification inside the Blastodinium genus.
Chatton (1920) proposed an arrangement of the Blastodinium genus into three main groups established based upon morphological characters. These groups correspond well to the different clusters defined in this study based upon the SSU RDNA gene analyses. Indeed, these clusters have been called "mangini", "contortum" and "spinulosum" in Fig. 5 in homology with Chatton's description. However, the genus Blastodinium is confirmed to be polyphyletic based upon the SSU rDNA gene (Skovgaard et al., 2007). More genetic markers (such as LSU rDNA genes (28S) or mitochondrial genes) are required to independently confirm this position.

\subsection{Dinospore distributions}

Blastodinium dinospores detected by FISH were thecate peridinioid dinoflagellates, in agreement with previous descriptions (Skovgaard et al., 2007; Skovgaard and Salomonsen, 2009). Although the three different probes were associated to relatively resembling individuals (by their mean size for example), several different morphotypes were in fact observed inside each cluster. This is congruent with the huge genetic diversity recorded, leading to the conclusion that each cluster cannot be simply reduced to a single morphotype. Indeed, this work likely underestimates the genetic diversity of Blastodinium since several morphotypes (BOUM17 and hyper-twisted $B$. contortum) could not be amplified by PCR, and probe BLA2 did not cover all of the sequences retrieved from this study. Thus, dinospore abundances in this study were likely underestimated. Observations of STD $(<15 \mu \mathrm{m})$ are rare for oligotrophic waters, even in the relatively well-studied Mediterranean Sea (Siokou-Frangou et al., 2010), probably because they are generally grouped with the nanoplanktonic flagellates. We detected maximal abundances of STD below the deep chlorophyll maximum (DCM) at station $\mathrm{A}$ and $\mathrm{C}$, an intriguing distribution in contrast with that of larger photosynthetic dinoflagellates which peak in the surface layer. Below the DCM, availability of photosynthetically active radiation is probably a limiting factor. Because chlorophyll was lost during the FISH procedure, we can but speculate on the trophic mode of Blastodinium dinospores. Most of Blastodinium species described are presumed to be at least partially autotrophic and produced spores that have chloroplasts (Chatton, 1920; Skovgaard et al., 2007). Photosynthetic thecate dinoflagellates resembling Blastodinium dinospores were recently reported from a large transect covering the Chile upwelling to the hyperoligotrophic waters of the South-East Pacific Ocean gyre based upon DAPI counts (Masquelier and Vaulot, 2008).

On the other hand, densities of Blastodinium dinospores may simply reflect the vertical distribution of their hosts rather than an ecological preference of the dinospore stage. If this is true, most of Blastodinium dinospores were produced at the DCM or just below at the three stations explored. This is in agreement with the maximal copepod abundance, which is generally observed close to the DCM (Herman, 
1983; Paffenhöfer and Mazzocchi, 2003; Peralba and Mazzocchi, 2004; Nowaczyk et al., 2011). Considered more in detail, it is known that Farranula and Oncaea, the two main copepod genera detected in our samples among Cyclopoida, rarely occur in the upper $30 \mathrm{~m}$ depth (Siokou-Frangou et al., 1997; Paffenhöfer and Mazzocchi, 2003). This distribution could then explain the absence of BMANG1-targeted cells in surface waters at the three stations. Similarly, C. paululus, C. pergens, C. arcuicornis, C. parapergens, and C. jobei avoid the surface (upper 25-50 m) when temperatures exceed $20^{\circ} \mathrm{C}$. However, $C$. furcatus is almost exclusively restricted to the upper part of the thermocline during the same period (Paffenhöfer and Mazzocchi, 2003; Peralba and Mazzocchi, 2004). These observations may help explain the presence of Blastodinium dinospores in surface waters belonging to the "contortum" and "spinulosum" clusters, both known to infect C. furcatus.

\subsection{Ecological relevance in marine oligotrophic waters}

Infections on crustaceans by unicellular parasites is well known as a powerful factor controlling host mortality and fecundity in freshwater systems, where prevalences could reach values higher than $80 \%$ in highly productive systems with dense populations of planktonic crustaceans (Green, 1974; Duncan et al., 2006). However, this is not the case for marine pelagic systems where parasite-host interactions are poorly investigated. Based on these antecedents, the prevalences recorded in this study are impressive, especially considering the situation of low biological production and low densities of host populations. Frequencies of infection reported in our study, based on our DNA-stain screening method, are likely over-estimates as only $85 \%$ of probable infections suspicions in Corycaeida at station $\mathrm{C}$ were subsequently confirmed by dissections. However, even considering a false-positive error rate of $15 \%$, the infection rates within Corycaeida and Calanoida groups are among the highest values reported from the literature. However, it should be noted that these frequencies represent grouped infections by very different Blastodinium species found coexisting at station C (some inside the same copepod species). This is in agreement with Sewell (1951) who reported the presence of up to 9 different Blastodinium species from a single sample collected in the Arabian Sea infecting a wide range of copepods.

Blastodinium occurrences are reported to have a marked seasonality, with highest prevalences observed during warmer period of the year in the Mediterranean Sea (Chatton, 1920; Skovgaard and Saiz, 2006). Concomitantly, Chatton (1920) also reported slower sporulations at low temperature. Thus, the summer conditions during the BOUM cruise were probably likely favourable for Blastodinium spp. Such parasitic association may be favoured by the severe depletion of nutrients, generally linked to summer time in more coastal waters. Although more data are required to ex- plore this hypothesis, we can conclude that ultra-oligotrophy of waters is not a limiting factor for these parasites. This was also the case for another parasite, the Amoebophryidae (Syndiniales), which were found infecting several microplanktonic dinoflagellate species at high prevalences at same stations (Siano et al., 2011). The maximal density of Syndiniales dinospores were estimated to be around 50 cells ml ${ }^{-1}$ in oligotrophic waters, 10 times more concentrated than Blastodinium dinospores. Converted to biomass, both parasites substantially contribute to the organic carbon, which would be directly consumable by herbivores and/or secondary predators. Indeed, the fate of these free-living parasitic stages is an intriguing question in both cases.

Blastodinium infections are supposed to be initiated during the early stages of copepod development (Chatton, 1920). However, there is a drastic partitioning between nauplii and dinospores (with a significant negative correlation). In other part, nauplii are known to largely consume prey items smaller than the Blastodinium dinospores. In contrast, copepodites do feed on prey of dinospore-size, 10-20 $\mu \mathrm{m}$ (Wilson, 1973). Based on these considerations, it appears likely that copepodites are the first stage infected by Blastodinium spp.

\section{Conclusions}

Substantial copepod infections by Blastodinium spp. occur in the oligotrophic to ultra-oligotrophic waters of the Mediterranean Sea. Blastodinium spp. are polyphyletic and infect a wide range of copepod taxa. The free-living stages (or dinospores) of the parasite Blastodinium spp. occur in the water column and can be detected by FISH technique. They formed relatively dense communities located at the DCM or slightly below, a vertical distribution similar to that of their copepod hosts. Interestingly, deep intense blooms of diatoms were also detected during the BOUM transect, especially at station C (Crombet et al., 2011). Such phenomenon may be favoured by hydrophysical meso- and microscale mechanisms. The trophic mode of the dinospores and their ability to persist outside a copepod host at relatively high density are among the many questions which remain concerning these organisms.

\section{Supplementary material related to this article is available online at: http://www.biogeosciences.net/8/2125/2011/ bg-8-2125-2011-supplement.pdf.}

Acknowledgements. Authors wish to thank Thierry Moutin, chief of the operation during BOUM cruise and E. M. Bendif for collecting samples on board. We would like to thank F. Gomez for phytoplanktonic counts made on BOUM samples, Claude Courties and Laëtitia Bariat for their analyses of nanoplantkon by flow cytometry, and E. Bigeard for technical help with sequences. We 
would like to warmly thank D. Wayne Coats that kindly made micrographs in Fig. $2 \mathrm{f}-\mathrm{g}$, Sergey Karpov for its dexterity to extract Blastodinium from infected copepods, and John Dolan for data on ciliates and to critically read this manuscript. C. A. S. was financed by a Conicyt doctoral fellowship (Chilean government). This work was financially supported by the French ANR AQUAPARADOX.

Edited by: T. Moutin

\section{References}

Chatton, E.: Les péridiniens parasites. Morphologie, reproduction, éthologie, Arch. Zool. Exp. Gen., 59, 1-475, 1920.

Chomczynski, P. and Sacchi, N.: The single-step method of RNA isolation by acid guanidinium thiocyanate-phenol-chloroform extraction: twenty-something years on, Nat. Protoc., 1, 581-585, 2006.

Christaki, U., Van Wambeke, F., Lefevre, D., Lagaria, A., Prieur, L., Pujo-Pay, M., Grattepanche, J.-D., Colombet, J., Psarra, S., Dolan, J. R., Sime-Ngando, T., Conan, P., Weinbauer, M. G., and Moutin, T.: Microbial food webs and metabolic state across oligotrophic waters of the Mediterranean Sea during summer, Biogeosciences, 8, 1839-1852, doi:10.5194/bg-8-1839-2011, 2011.

Coats, D. W., Bachvaroff, T., Handy, S. M., Kim, S., GárateLizárraga, I., and Delwiche, C. F.: Prevalence and phylogeny of parasitic dinoflagellates (genus Blastodinium) infecting copepods in the Gulf of California, CICIMAR Oceánides, 23, 67-77, 2008.

Crombet, Y., Leblanc, K., Quéguiner, B., Moutin, T., Rimmelin, P., Ras, J., Claustre, H., Leblond, N., Oriol, L., and Pujo-Pay, M.: Deep silicon maxima in the stratified oligotrophic Mediterranean Sea, Biogeosciences, 8, 459-475, doi:10.5194/bg-8-4592011, 2011.

Duncan, A. B., Mitchell, S. E., and Little, T. J.: Parasite-mediated selection and the role of sex and diapauses in Daphnia, J. Evolution. Biol., 19, 1183-1189, 2006.

Green, J.: Parasites and epibionts of Cladocera, Trans. Zool. Soc. Lond., 32, 417-515, 1974.

Guindon, S., Lethiec, F., Duroux, P., and Gascuel, O.: PHYML Online - a web server for fast maximum likelihood-based phylogenetic inference, Nucleic Acids Res., 33, W557-W559, 2005.

Herman, A. W.: Vertical distribution patterns of copepods, chlorophyll, and production in northeastern Baffin Bay, Limnol. Oceanogr., 28, 709-719, 1983.

Huelsenbeck, J. P. and Ronquist, F.: MrBayes: Bayesian inference of phylogenetic trees, Bioinformatics, 17, 754-755, 2001.

Ianora, A., Mazzocchi, M. G., and Scotto di Carlo, B.: Impact of parasitism and intersexuality on Mediterranean populations Paracalanus parvus (Copepoda:Calanoida), Dis. Aquat. Organ., 3, 29-36, 1987.

Ianora, A., Scotto di Carlo, B., Mazzocchi, M. G., and Mascellaro, P.: Histomorphological changes in the reproductive condition of parasitized marine planktonic copepods, J. Plankton Res., 12, 249-258, 1990.

Masquelier, S. and Vaulot, D.: Distribution of micro-organisms along a transect in the South-East Pacific Ocean (BIOSOPE cruise) using epifluorescence microscopy, Biogeosciences, 5, 311-321, doi:10.5194/bg-5-311-2008, 2008.
Moutin, T., Van Wambeke, F., and Prieur, L.: Introduction to the Biogeochemistry from the Oligotrophic to the Ultraoligotrophic Mediterranean (BOUM) experiment, Biogeosciences, in preparation, 2010.

Nowaczyk, A., Carlotti, F., Thibault-Botha, D., and Pagano, M.: Metazooplankton diversity, community structure and spatial distribution across the Mediterranean Sea in summer: evidence of ecoregions, Biogeosciences Discuss., 8, 3081-3119, doi:10.5194/bgd-8-3081-2011, 2011.

Paffenhöfer, G.-A. and Mazzocchi, M. G.: Vertical distribution of subtropical epiplanktonic copepods, J. Plankton Res., 25, 11391156, 2003.

Pasternak, A. F., Arashkevich, Y. G., and Sorokin, Y. S.: The role of the parasitic algal genus Blastodinium in the ecology of planktic copepods, Oceanology, 24, 748-751, 1984.

Peralba, A. and Mazzocchi, M. G.: Vertical and seasonal distribution of eight Clausocalanus species (Copepoda: Calanoida) in oligotrophic waters, ICES J. Mar. Sci., 61, 645-653, 2004.

Posada, D.: jModelTest: Phylogenetic model averaging, Mol. Biol. Evol., 25, 1253-1256, 2008.

Sewell, R. B. S.: The epibionts and parasites of the planktonic Copepoda of the Arabian Sea. John Murray expedition 1933-34, Sci. Rep. Br. Mus. Nat. Hist., 9, 255-394, 1951.

Shields, J. D.: The parasitic dinoflagellates of marine crustaceans, Annual Review of Fish Diseases, 4, 241-271, 1994.

Siano, R., Alves-de-Souza, C., Foulon, E., Bendif, El M., Simon, N., Guillou, L., and Not, F.: Distribution and host diversity of Amoebophryidae parasites across oligotrophic waters of the Mediterranean Sea, Biogeosciences, 8, 267-278, doi:10.5194/bg-8-267-2011, 2011.

Siokou-Frangou, I., Christou, E. D., Fragopoulu, N., and Mazzocchi, M. G.: Mesozooplankton distribution from Sicily to Cyprus (Eastern Mediterranean): II. Copepod assemblages, Oceanol. Acta, 20, 537-548, 1997.

Siokou-Frangou, I., Christaki, U., Mazzocchi, M. G., Montresor, M., Ribera d'Alcalá, M., Vaqué, D., and Zingone, A.: Plankton in the open Mediterranean Sea: a review, Biogeosciences, 7, 1543-1586, doi:10.5194/bg-7-1543-2010, 2010.

Skovgaard, A.: Infection with the dinoflagellate parasite Blastodinium spp. in two Mediterranean copepods, Aquat. Microb. Ecol., 38, 93-101, 2005.

Skovgaard, A. and Saiz, E.: Seasonal occurrence and role of protistan parasites on coastal marine zooplankton, Mar. Ecol.-Prog. Ser., 327, 37-49, 2006.

Skovgaard, A. and Salomonsen, X. M.: Blastodinium galatheanum sp. nov. (Dinophyceae) a parasite of the planktonic copepod Acartia negligens (Crustacea, Calanoida) in the central Atlantic Ocean, Eur. J. Phycol., 44, 425-438, 2009.

Skovgaard, A., Massana, R., and Saiz, E.: Parasitic species of the genus Blastodinium (Blastodiniphyceae) are peridinioid dinoflagellates, J. Phycol., 43, 553-560, 2007.

Vane, F. R.: The distribution of Blastodinium hyalinum in the North Sea, Challenger Soc., 3, 23-24, 1952.

Wilson, D. S.: Food size selection among copepods, Ecology, 54, 909-914, 1973. 